\title{
Comparative transcriptome analysis reveals that tricarboxylic acid cycle-related genes are associated with maize CMS-C fertility restoration
}

Yongming Liư ${ }^{\dagger}$ Gui Wei ${ }^{\dagger}$, Yuanyan Xia, Xiaowei Liu, Jin Tang, Yanli Lu, Hai Lan, Suzhi Zhang, Chuan Li and Moju Cao*

\begin{abstract}
Background: C-type cytoplasmic male sterility (CMS-C) is one of the three major types of cytoplasmic male sterility (CMS) in maize. Rf4 is a dominant restorer gene for CMS-C and has great value in hybrid maize breeding, but little information concerning its functional mechanism is known.

Results: To reveal the functional mechanism of Rf4, we developed a pair of maize near-isogenic lines (NILs) for the Rf4 locus, which included a NIL_rf4 male-sterile line and a NIL_Rf4 male fertility-restored line. Genetic analysis and molecular marker detection indicated that the male fertility of NIL_Rf4 was controlled by Rf4. Whole-genome sequencing demonstrated genomic differences between the two NILs was clustered in the Rf4 mapping region. Unmapped reads of NILs were further assembled to uncover Rf4 candidates. RNA-Seq was then performed for the developing anthers of the NILs to identify critical genes and pathways associated with fertility restoration. A total of 7125 differentially expressed genes (DEGs) were identified. These DEGs were significantly enriched in 242 Gene Ontology (GO) categories, wherein 100 DEGs were involved in pollen tube development, pollen tube growth, pollen development, and gametophyte development. Homology analysis revealed 198 male fertility-related DEGs, and pathway enrichment analysis revealed that 58 DEGs were enriched in cell energy metabolism processes involved in glycolysis, the pentose phosphate pathway, and pyruvate metabolism. By querying the Plant Reactome Pathway database, we found that 14 of the DEGs were involved in the mitochondrial tricarboxylic acid (TCA) cycle and that most of them belonged to the isocitrate dehydrogenase (IDH) and oxoglutarate dehydrogenase (OGDH) enzyme complexes. Transcriptome sequencing and real-time quantitative PCR (qPCR) showed that all the above TCA cycle-related genes were up-regulated in NIL_Rf4. The results of our subsequent enzyme-linked immunosorbent assay (ELISA) experiments pointed out that the contents of both the IDH and OGDH enzymes accumulated more in the spikelets of NIL_Rf4 than in those of NIL_rf4.
\end{abstract}

Conclusion: The present research provides valuable genomic resources for deep insight into the molecular mechanism underlying CMS-C male fertility restoration. Importantly, our results indicated that genes involved in energy metabolism, especially some mitochondrial TCA cycle-related genes, were associated with maize CMS-C male fertility restoration.

Keywords: Maize, Cytoplasmic male sterility, Fertility restoration, Oxoglutarate dehydrogenase, Isocitrate dehydrogenase, Transcriptome sequencing

\footnotetext{
* Correspondence: mojupp@163.com

${ }^{\dagger}$ Yongming Liu and Gui Wei contributed equally to this work.

Key Laboratory of Biology and Genetic Improvement of Maize in Southwest

Region of Ministry of Agriculture, Maize Research Institute, Sichuan

Agricultural University, Chengdu 611130, China
}

(c) The Author(s). 2018 Open Access This article is distributed under the terms of the Creative Commons Attribution 4.0 International License (http://creativecommons.org/licenses/by/4.0/), which permits unrestricted use, distribution, and reproduction in any medium, provided you give appropriate credit to the original author(s) and the source, provide a link to the Creative Commons license, and indicate if changes were made. The Creative Commons Public Domain Dedication waiver (http://creativecommons.org/publicdomain/zero/1.0/) applies to the data made available in this article, unless otherwise stated. 


\section{Background}

Plant cytoplasmic male sterility (CMS) involves the shortage of functional pollen grains while female gametes are still normal. CMS is caused by a chimeric opening reading frame (ORF) resulting from spontaneous mitochondrial genome rearrangement [1]. Some nuclear genes that are referred to as restorer of fertility $(R f)$ genes can rescue CMS at different levels, such as the genomic, mRNA, protein, and metabolic levels [24]. The CMS/Rf system not only serves as an ideal model for studying communication between the nucleus and mitochondria but also represents a valuable tool for exploiting heterosis in hybrid seed production $[2,5]$. At present, deep insight into plant CMS fertility restoration contributes to its wide utilization in hybrid seed production [6].

In maize, male-sterile cytoplasm can be divided into three categories according to the fertility restoration patterns displayed in the $F_{1}$ hybrids: Texas (T), USDA (S) and Charrua (C) [7]. Among plants of these categories, C-type cytoplasmic male sterility (CMS-C) presents a stable male sterility and positively affects grain yield, contributing to its great application value in maize hybrid seed production $[8,9]$. However, the fertility restoration mechanism of CMS-C appears to be highly complex. Previous studies have indicated that, with the exception of the two dominant $R f 4$ and Rf5 genes, quantitative trait loci (QTLs) are also involved in maize CMS-C fertility restoration [10-12]. These QTLs always partially restore CMS-C male fertility, which makes their use difficult. Moreover, $R f-I$ on chromosome 7 can inhibit the function of $R f 5$ but not Rf4 [13]. Furthermore, the genetic background of sterile lines might also affect the function of $R f$ genes in CMS-C, and the number of functional $R f$ gene might diverge when facing different male-sterile lines [14]. Overall, the complex mechanism of CMS-C fertility restoration brings about serious challenges to the application of CMS-C in hybrid seed production. Rf4 can completely rescue most of the maize CMS-C lines and has great potential value in maize CMS-C hybrid popularization and utilization. Much work has been undertaken for $R f 4$, which was preliminarily mapped to the short arm of chromosome 8 [15-17]. Rf4 was further mapped to a $1.5 \mathrm{cM}$ interval $(520 \mathrm{~kb})$ that contained 12 candidate genes [18]. Rf4 was ultimately narrowed down to a $12 \mathrm{~kb}$ region at the tip of chromosome 8; this region contains two nuclear-targeted genes: GRMZM2G021276 and GRMZM2G582028 [19]. However, additional experimental evidence is needed to confirm the Rf4 candidate gene and to elucidate its functional mechanism.

Most restorer genes encode different pentatricopeptide repeat (PPR) proteins, enabling them both to be targeted to mitochondria where CMS genes and products are located and to bind to CMS transcripts [20,21]. Surprisingly, no PPR-encoded genes were found in the final mapping region of $R f 4$, suggesting that $R f 4$ might be a new type of restorer gene [18]. Elucidating the $R f 4$ functional mechanism would be interesting, which may provide novel insights into plant CMS fertility restoration. However, the probability of $R f 4$ encoding a PPR protein cannot be excluded because the reference genome of B73 is still incomplete and because B73 might even lack Rf4. In this study, comparative transcriptome sequencing was performed on Rf4 near-isogenic lines (NILs) to reveal the functional mechanism of $R f 4$.

\section{Methods}

\section{Plant materials}

In this study, a nearly isogenic line at the Rft locus (NIL_Rf4) was developed for comparative genome and transcriptome analyses. NIL_Rf4 was developed from the maize inbred donor line A619 (Rf4Rf4) and the CMS-C male-sterile recipient line C698-3 (rf4rf4) (NIL_rf4). Moreover, the male-fertile plants ( $>5$ plants) were backcrossed with the plants of maintainer line 698-3 (rf4rf4) to produce the subsequent generation of the backcross population. Briefly, plants from the $\mathrm{BC}_{4}$ and $\mathrm{BC}_{5}$ populations were used for phenotype and genotype characterization, male-fertile plants from both the $\mathrm{BC}_{5}$ population and line C698-3 were used for comparative genome and transcriptome analysis, and male-fertile plants from the $\mathrm{BC}_{6}$ population were used for measurements of isocitrate dehydrogenase (IDH) and oxoglutarate dehydrogenase $(\mathrm{OGDH})$ enzyme abundance. Specifically, fresh leaves from three NIL_Rf4 or NIL_rf4 individuals were separately mixed for genome sequencing. Moreover, spikelets at the pollen maturation stage with a length of $0.7-0.8 \mathrm{~cm}$ were collected from three individual fertile plants (NIL_Rf4_r1, NIL_Rf4_r2, and NIL_Rf4_r3) and three individual sterile plants (NIL_rf4_r1, NIL_rf4_r2, and NIL_rf4_r3) for transcriptome sequencing. The samples were frozen directly in liquid nitrogen and then stored at $-70{ }^{\circ} \mathrm{C}$.

\section{Phenotype and genotype characterization}

To characterize NIL_Rf4, the male fertility of each individual in backcross populations $\mathrm{BC}_{4}$ and $\mathrm{BC}_{5}$ was investigated. For male fertility, both anther exertion and pollen fertility were rated as we described previously [14]. Moreover, in that report, we developed a tightly linked Rf4 marker (5'-CGCACCTAACCGTCTCC-3', 5'-GCGCAAGTACGCCGTAC-3'). Here, the marker was used to confirm all plant genotypes in the $\mathrm{BC}_{5}$ backcross population. Genomic DNA from the fresh leaves of each plant was extracted using the modified cetyl-trimethylammonium bromide (CTAB) method [22]. PCR amplification was performed using Tsingke 
PCR Master Mix (Tsingke, China) in accordance with its specifications.

\section{Genome-Seq mapping, single nucleotide polymorphism (SNP) calling and annotation}

Genomic DNA was isolated from the fresh leaves of NIL_Rf4 $\left(\mathrm{BC}_{5}\right)$ and NIL_rf4 using a Plant Genomic DNA Kit (Tiangen, China). The concentration, purity, and integrity of the DNA samples were examined using 1\% agarose gels, a NanoDrop 2000 Spectrophotometer and a Qubit fluorometer (Thermo Fisher Scientific, USA). Afterward, the two DNA composites were sent to Novogene Technology Co., Ltd. (Beijing, China) for library construction and sequencing. Paired-end sequencing libraries were prepared for genome sequencing on an Illumina HiSeq 2500 analyser (Illumina, USA). The length of the reads was $150 \mathrm{bp}$, and paired ends were obtained. Before mapping, we removed the adaptor fragments, low-quality sequences $(\geq 50 \%$ of the bases with a quality score $\mathrm{Q} \leq 5)$, and impurities $(N>10 \%)$. BWA 0.7 .8 (parameters: mem -t $4-\mathrm{k} 32-\mathrm{M}$ $-\mathrm{R})$ was used to map the clean reads against the B73 reference genome sequence (ftp://ftp.ensemblgenomes.org/pub/release-31/plants/fasta/zea_mays/dna/). SNP calling was performed with SAMtools 0.1.19 software [23]. Low-quality SNPs with a base quality value $<20$ or with a read depth $<4$ or $>1000$ from the two composite sequences were excluded. The SNPs were categorized as exonic, intronic, intergenic, and splicing as well as within the untranslated region (UTR) based on their positions. Moreover, an average SNP index [24, 25] was calculated for both samples using a sliding window analysis with a $100 \mathrm{~kb}$ window size and a $10 \mathrm{~kb}$ increment.

Identification and characterization of non-reference genes Unmapped reads of NILs were used to assemble contigs by SOAPdenovo with default parameters. Novel gene models were predicted using Genewise and AUGUSTUS. Then, each novel gene putative function was annotated using the InterPro (http://www.ebi.ac.uk/ interpro/), KEGG (https://www.kegg.jp/), Swissprot (https://www.uniprot.org/), TrEMBL (https://www.uniprot.org/), and GO (http://www.geneontology.org/) databases. HMMER 3.0 software with the Hidden Markov (HMM) profile of PPR domain (PF01535) was used to identify PPR genes among novel genes. TargetP (http://www.cbs.dtu.dk/services/TargetP/) was used to predict each novel gene subcellular location.

\section{RNA-Seq mapping}

The total RNA of six samples, which included three NIL_rft samples (NIL_rf4_r1, NIL_rf4_r2, and NIL_rf4_r3) and three NIL_Rf4 (BC 5$)$ samples (NIL_Rf4_r1, NIL_Rf4_r2, and
NIL_Rf4_r3), was respectively extracted using a Qiagen RNeasy Kit (Qiagen, USA). The concentration, purity, and integrity of the RNA samples were examined using $1 \%$ agarose gels, a NanoDrop 2000 Spectrophotometer (Thermo Fisher Scientific, USA), and an Agilent Bioanalyzer 2100 System (Agilent Technologies, USA). DNase I was used to digest the residual genomic DNA. The samples were subsequently sent to Chengdu Basebio Biotechnology Company (China) for library construction and transcriptome sequencing on an Illumina $\mathrm{HiSeq}^{\mathrm{Tm}} 2500$ platform (Illumina, USA). Raw reads (150 bp paired-end) were filtered in accordance with the same method used for Genome-Seq. Clean reads from the RNA-Seq were mapped via TopHat v2.0.9 to the same version of the B73 reference genome as that used for Genome-Seq. Only reads that uniquely mapped to the reference genome were used for further analysis.

\section{Identification of differentially expressed genes (DEGs) and functional analysis}

Transcripts per million (TPM) was used to calculate the expression of each transcript [26]. Based on the normalized transcript expression, the $P_{-}$values were corrected in accordance with the Benjamini-Hochberg method, and $Q$ Qvalue (corrected $P_{-}$value) $<0.01$ served as the threshold for screening the DEGs. All the DEGs were then subjected to Gene Ontology (GO) analysis (http://bioinfo.cau.edu.cn/agriGO/analysis.php) and Kyoto Encyclopedia of Genes and Genomes (KEGG) pathway analysis (http:// www.genome.jp/kegg/) via hypergeometric tests. In the above enrichment analyses, the $P_{-}$values were corrected with the default methods on the websites, and Q_value $\leq 0.05$ was used as the threshold for selecting significantly enriched GO terms and KEGG pathways.

To identify the potential genes involved in altering male fertility, all the DEGs with an $E_{-}$value $<1 \mathrm{e}^{-30}$ were queried in the Plant Male Reproduction Database (PMRD) (http://202.120.45.92/addb/), which contains 548 male fertility-related genes in Arabidopsis. The maize gene sequences were retrieved from MaizeGDB (ftp://ftp.ensemblgenomes.org/pub/plants/release-31/ fasta/zea_mays). Afterward, all target gene expression data (fragments per kilobase of exon per million fragments mapped (FPKM)) in various tissues were obtained from qTeller (www.qteller.com). The FPKM values were $\log _{2}$ normalized (FPKM +1$)$, after which the Z-scores for each gene were calculated to assess their tissue expression specificity. Moreover, the corresponding information on PPR genes in maize was obtained from a recent report [27].

Enzyme-linked immunosorbent assay (ELISA) detection of IDH and OGDH abundance in spikelets

A total of $100 \mathrm{mg}$ of spikelets whose length ranged from $0.7-0.8 \mathrm{~cm}$ at the pollen maturation stage (the same 
stage as that used for transcriptome sequencing) of three individual sterile NIL_rf4 plants and three individual fertile NIL_Rf4 plants $\left(\mathrm{BC}_{6}\right)$ was collected for IDH and $\mathrm{OGDH}$ content measurements. Each sample was fully pelletized in $900 \mu \mathrm{L}$ of PBS $(0.01 \mathrm{~mol} / \mathrm{L}, \mathrm{pH}=7.2-7.4)$, chilled on ice and ultrasonicated for 30 min with $300 \mathrm{~W}$ of power to obtain mitochondrial IDH and OGDH. The homogenates were then centrifuged $(5000 \mathrm{~g}, 10 \mathrm{~min}$, $4^{\circ} \mathrm{C}$ ), after which the supernatants were ultimately used for IDH and OGDH content measurements via ELISA kits (Nanjing SenBeijia Biological Technological Co., Ltd., China) in accordance with the manufacturer's protocol. Each sample was tested three times, and statistical differences were tested by independent Student's $t$-tests.

\section{Real-time quantitative PCR (qPCR) analysis}

To measure the expression levels of the tricarboxylic acid (TCA) cycle-related genes and validate the accuracy of the transcriptome sequencing, 12 and 9 genes were respectively selected to analyse their expression via qPCR (see primer information in Additional file 1). 18S RNA was used as an internal control. The RNA samples were prepared in the same manner as those used for RNA-Seq. One microgram of total RNA from each sample was used to synthesize cDNA via a PrimeScript ${ }^{\text {tm }}$ RT Reagent Kit (TaKaRa, China) with RT-Primer Mix. qPCR was conducted on a CFX96 $6^{\text {to }}$ Real Time system (Bio-Rad, USA) in conjunction with SYBR Green Real-time PCR Master Mix (TaKaRa, China). The comparative threshold cycle $(\mathrm{CT})$ method $\left(2^{-\Delta \Delta \mathrm{Ct}}\right)$ was then used to assess the relative expression level of each gene [28].

\section{Results}

\section{Characterization of NIL_Rf4}

Only two phenotypes, complete male fertility and complete male sterility, were observed in the $\mathrm{BC}_{4}$ and $\mathrm{BC}_{5}$ populations, and the male-fertile plants could form normal pollen and flowered normally (see Additional file 2). We observed a 1:1 ratio in terms of the number of plants that produced normal pollen and the number of plants that displayed aborted pollen in the $\mathrm{BC}_{4}$ and $\mathrm{BC}_{5}$ populations, indicating that male fertility was controlled by one single nuclear gene (see Additional file 3). In addition, we observed that the male fertility of the $\mathrm{BC}_{5}$ population co-segregated with the tightly linked the Rf4 marker (see Additional file 4). The above results indicated that Rf4 was successfully transferred to NIL_Rft.

\section{Genomic profiles of NILs}

To reveal genomic variations between the NILs, polymorphic SNPs were detected using whole-genome sequencing. Total amounts of 98,331,340 and 83,494,528 short reads were obtained from NIL_Rf4 (7.44× depth coverage) and NIL_rf4 (6.48× depth coverage), respectively. These reads were then aligned to the $\mathrm{B} 73$ reference genome. A total of 1,216,260 SNPs between NIL_Rf4 and NIL_rf4 were identified throughout the whole genome, of which 26,383 SNPs were located in exons, 58,671 SNPs were located in introns, 169 SNPs were located at the variable splicing sites, 41,150 SNPs were located in UTRs, and 1,089,887 SNPs were located in intergenic regions (Fig. 1a). The above results showed that these SNPs were located mainly in noncoding regions. The genome sequencing results indicated that GRMZM2G122850 was

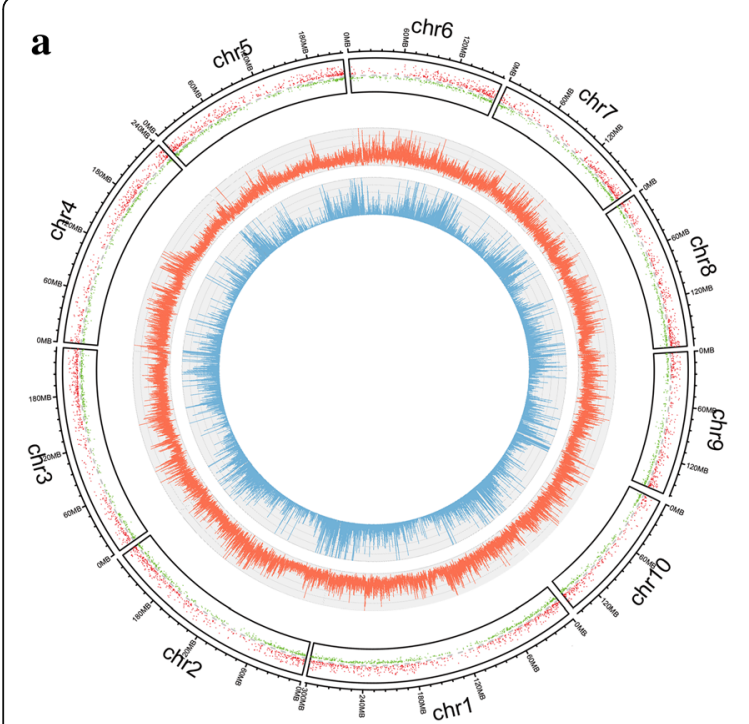

b

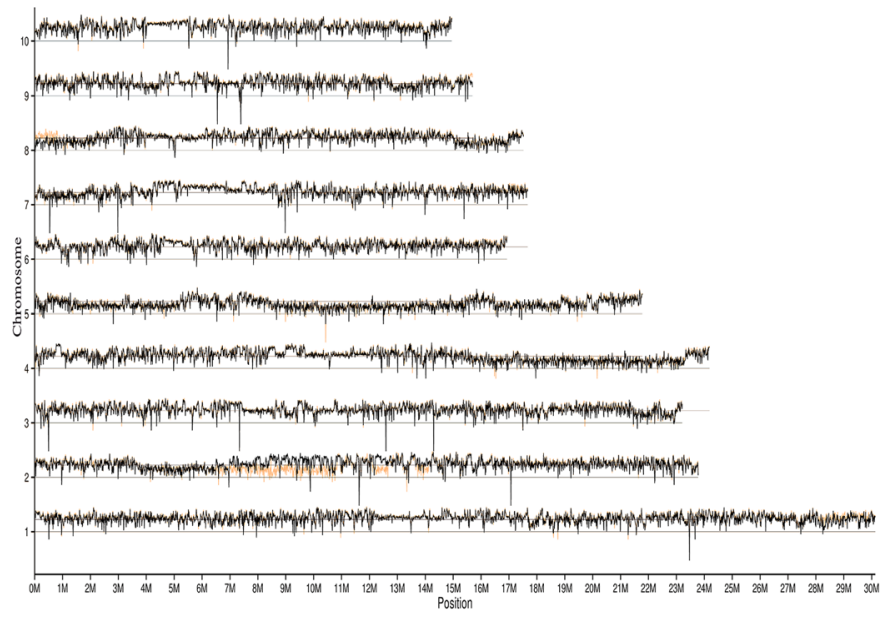

Fig. 1 a Distribution of SNPs and DEGs between NIL_Rf4 and NIL_rf4. From inner circle to the outer circle, the first and the second circles indicate the distribution of SNPS within exons and genome, respectively. In the third circle, the green dots represent up-regulated transcripts in NIL_Rf4, while the red dots represent down-regulated transcripts. b SNP index graphs of the NIL_Rf4 (yellow lines) and NIL_rf4 (black lines) 
the unique gene that harboured amino acid changes in the Rf4 mapping region. GRMZM2G122850 encodes a selenium-binding protein that contains 390 amino acid residues; subcellular localization prediction via TargetP showed that this protein might be targeted to the mitochondria. Four SNPs were found to be located in its coding sequence and caused two missense mutations: $\mathrm{R} 316 \mathrm{H}$ and D359N. These SNPs were confirmed via the dideoxy chain-termination method (see Additional file 5), and their potential effects need to be studied further.

Next, a SNP index was calculated for each identified SNP, and all SNP indexes of the two samples were plotted onto the whole maize genome (Fig. 1b). We found that the NILs shared similar SNP indexes across the majority of the maize genome. However, a series of biased SNP indexes were observed on the short arm of chromosome 8 from 0 to $1 \mathrm{Mb}$, which is consistent with the Rf4 mapping region [19]. These results demonstrated that the genomic variations between NILs were located mainly near the $R f 4$ locus.

\section{Putative functions of novel genes}

As stated before, the reference genome of B73 may not be complete and it may even miss the sequence of $R f 4$. In this study, those unmapped reads were further assembled and annotated. We obtained 2890 putative genes in NILs (see Additional file 6) and most of their functions $(>90 \%)$ could be annotated (see Additional file 7). Among the novel genes, 645 genes could be targeted to the mitochondria and one PPR protein (Contig.4402.1) was found. These novel genes might help to uncover Rf4 candidates in the future.

\section{Transcriptomic profiles of NILs}

Six libraries, which consisted of three biological replicates per line, were prepared for RNA-Seq. A total of 265 million $150 \mathrm{bp}$ paired-end reads were obtained for 6 samples; the reads for each sample ranged from 37 million to 54 million. The read length of all samples combined was $>37 \mathrm{~Gb}$, representing an approximately 15-fold coverage of the maize genome. Approximately $71 \%$ of these short reads could be uniquely mapped to the reference genome (Table 1). Pearson correlation coefficient analysis revealed that the $r^{2}$ value was greater than 0.93 for both groups and revealed both high correlations between and slight variability among biological replicates, showing the reliability of the transcriptome sequencing data (Fig. 2).

\section{Validation and functional characterization of DEGs}

To detect transcriptomic variation during male fertility conversion, the expression levels of all genes expressed in developing spikelets were compared between NIL_Rf4 and NIL_rf4 (Fig. 1a). In total, 7125 DEGs
Table 1 Summary of RNA-Seq yields and alignments for six samples

\begin{tabular}{lllllll}
\hline Samples & $\begin{array}{l}\text { Clean } \\
\text { reads }\end{array}$ & $\begin{array}{l}\text { Base } \\
(\mathrm{G})\end{array}$ & $\begin{array}{l}\mathrm{Q} 20 \\
(\%)\end{array}$ & $\begin{array}{l}\text { Q30 } \\
(\%)\end{array}$ & $\begin{array}{l}\text { GC } \\
(\%)\end{array}$ & $\begin{array}{l}\text { Map rate } \\
(\%)\end{array}$ \\
\hline NIL_Rf4_r1 & $39,893,186$ & 5.98 & 97 & 92 & 57 & 73 \\
NIL_Rf4_r2 & $44,696,350$ & 6.70 & 97 & 93 & 59 & 72 \\
NIL_Rf4_r3 & $37,224,984$ & 5.58 & 97 & 92 & 59 & 73 \\
NIL_rf4_r1 & $54,907,140$ & 8.23 & 97 & 93 & 56 & 69 \\
NIL_rf4_r2 & $43,082,408$ & 6.46 & 97 & 93 & 57 & 68 \\
NIL_rf4_r3 & $45,717,652$ & 6.85 & 97 & 92 & 57 & 71
\end{tabular}

with 8125 transcripts were identified, the latter of which $91.22 \%$ (7740/8125) were up- or down-regulated by $\geq 2.0$-fold. Among the 7125 DEGs, 3873 genes were up-regulated in NIL_Rf4, and 3252 genes were down-regulated. The abundance of DEGs suggested that changes in gene expression were active during the fertility restoration of CMS-C maize. By combining our Genome-Seq data, we identified a total of 1679 DEGs that had exonic SNPs throughout the whole genome (Fig. 1a and Additional file 8). Additional analyses of these DEGs might help to reveal the fertility restoration mechanism of $R f 4$. To verify the accuracy of the transcriptome changes revealed by RNA-Seq in this study, the transcript levels of nine randomly selected DEGs were subsequently examined via qPCR (Fig. 3). The expression patterns of these nine genes obtained by qPCR were highly consistent with the results of RNA-Seq $\left(r^{2}=0.9536\right)$, which confirmed the reliability of the transcriptome sequencing results.

To determine their putative function, the DEGs were subjected to GO analysis. A total of 5269 DEGs were annotated with $4810 \mathrm{GO}$ terms. Within the biological

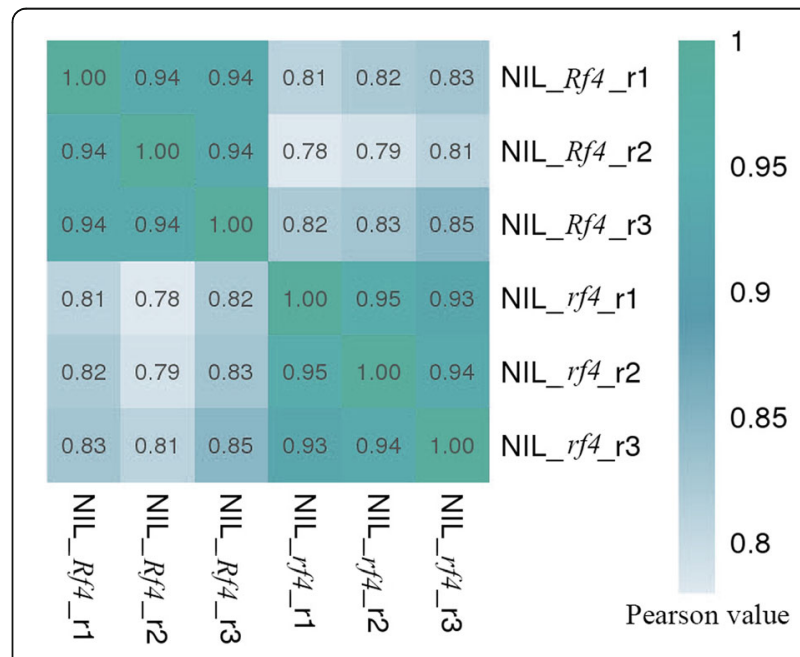

Fig. 2 Pearson correlation coefficient analysis of the transcriptome data for three biological replicates 


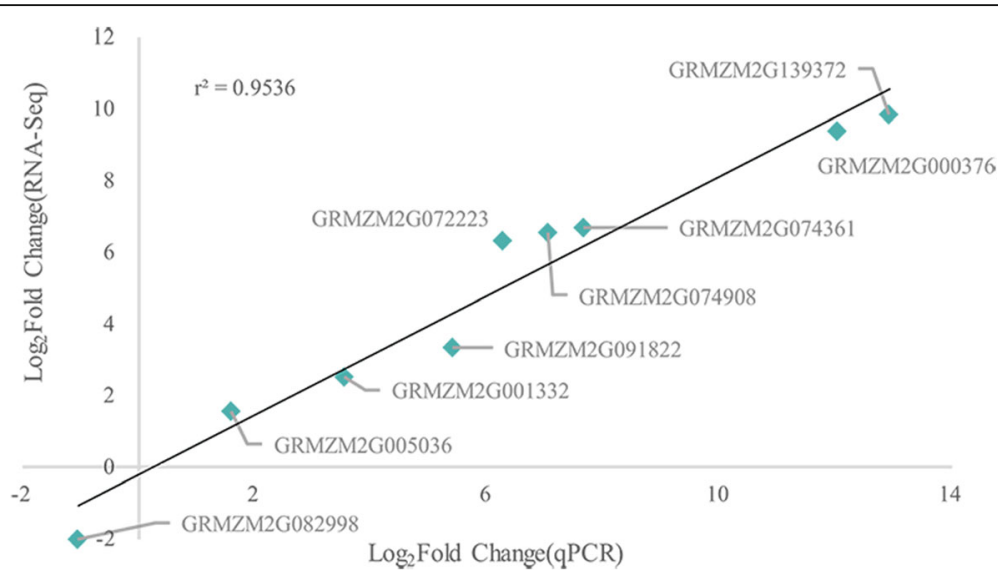

Fig. 3 Correlation of gene expression levels estimated by RNA-Seq and $\mathrm{PPCR}$. The $x$-axis and $y$-axis indicate relative expression values from $q P C R$ and RNA-Seq, respectively. Both values are $\log _{2}$ normalized. The $r$ value represents the Pearson correlation coefficient

process category, metabolic process, cellular process, and single-organism process were the top three abundant clusters. Under the cell component category, there were 451 enriched GO terms, and most of those genes were categorized as cell and cell part. With respect to the molecular function category, binding and catalytic activity were the most abundant subcategories. In addition, hypergeometric tests revealed 242 significantly enriched GO terms (see Additional file 9). Among the 242 GO terms, 4 terms were associated with 100 DEGs directly involved in pollen formation: pollen tube development (GO0048868), pollen tube growth (GO0009860), pollen development (GO000 9855), and gametophyte development (GO0048229). RNA-Seq revealed that 74 of the 100 genes associated with the four abovementioned GO terms were up-regulated in the male-fertile NIL_Rf4 plants (Fig. 4a), indicating that most of these genes play a positive regulatory role in maize pollen formation. Moreover, Euler diagram analysis revealed that most of these genes have various functions in pollen development (Fig. 4b). Importantly, four of them, GRMZM 2G170400 (phosphoethanolamine N-methyltransferase 3), GRMZM2G060886 (S-adenosyl-L-methionine-dependent methyltransferase), GRMZM2G122296 (phosphoethanolamine $\mathrm{N}$-methyltransferase 1-like), and GRMZM2G113506 (galacturonosyltransferase), are associated with all of the GO terms related to pollen development, implying their crucial effect on pollen development.

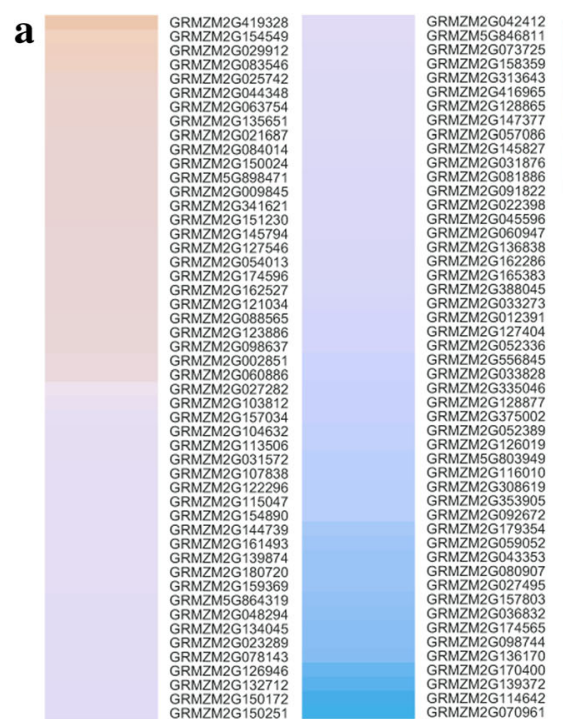

\section{b}

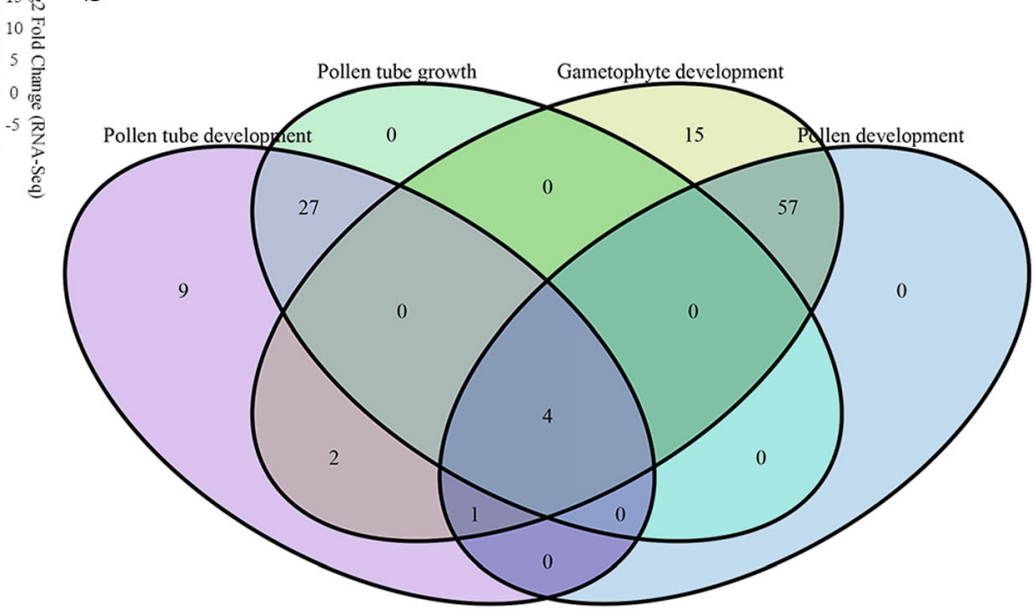

Fig. 4 Expression (a) and Euler diagram (b) analyses of DEGs related to pollen development 


\section{Identification of male fertility-related DEGs}

To identify key genes related to stamen development, the DEGs were aligned with 548 male Arabidopsis reproductive genes retrieved from the PMRD. A total of 198 genes were highly homologous to these Arabidopsis male reproductive genes; the cut-off $E_{-}$value was $<1 \mathrm{e}^{-30}$ (see Additional file 10). Among these target genes, 63 were preferentially expressed in maize anthers and tassels (see Additional file 11), suggesting that they might play a critical role in maize male reproduction. Most of the Rf proteins are encoded by the PPR gene family. To reveal potential PPR genes involved in maize CMS-C fertility restoration, 56 differentially expressed PPR proteins were observed, among which 16 and 28 are located in the mitochondrion and chloroplast, respectively (see Additional file 12). However, only two differentially expressed PPR genes, ZmPPR432 (GRMZM5G851564) and ZmPPR443 (GRMZM2G050485), were found on chromosome 8 , but both were far from the mapping region of Rf4 and could not be the Rf4 candidate gene.

\section{Identification of energy metabolism-related DEGs}

Plant male fertility conversion is tightly associated with energy metabolism, and energy deficiency may cause male sterility $[2,29]$. To gain a deep insight into the energy mechanism underlying CMS-C maize fertility restoration, 58 DEGs were found via KEGG analysis to participate in cell energy metabolism processes such as glycolysis, the pentose phosphate pathway, and pyruvate metabolism (Table 2). Among the 58 energy metabolism-related genes, 31 and 27 were up-regulated and down-regulated in NIL_Rf4, respectively. GRMZM2G154007, which encodes an alcohol dehydrogenase-like 2 protein, was the most up-regulated gene (fold change $=4096$ ), whereas GRMZM2 G345493, which encodes a fructose-bisphosphate aldolase 7 protein, was the most down-regulated gene (fold change $=-2048$ ). Interestingly, two glycolysis-related genes ( $G$ RMZM5G824600 and GRMZM2G071630) were not expressed in NIL_Rf4 or NIL_rf4, respectively. The different expression levels of the energy metabolism-related genes indicated the potential different energy levels between NIL_rf4 and NIL_Rf4 and that energy metabolism processes might play a key role in CMS-C fertility restoration.

\section{The abundance of IDH and OGDH in the mitochondrial} TCA cycle were associated with fertility restoration

Our KEGG analysis results above showed the probable different energy metabolism levels between NIL_Rf4 and NIL_rf4. The mitochondrial TCA cycle plays a crucial role in energy metabolism [30]. As such, all DEGs were queried in the Plant Reactome Pathway database (http:// plantreactome.oicr.on.ca/), and fourteen DEGs that participate in the mitochondrial TCA cycle were identified. Among these DEGs, GRMZM2G079538/GRMZ M5G807639 and GRMZM2G142863/GRMZM2G151041 are duplicate genes. The RNA-Seq data demonstrated that these genes were all up-regulated in NIL_Rf4 (Fig. 5), and the qPCR results confirmed the changes in their expression between NIL_Rf4 and NIL_rf4 (Fig. 6). Expression profile analysis revealed that these genes were expressed mainly in the anthers and tassels (see Additional file 13). We also used GPCR to explore the expression levels of these genes in developing anthers and leaves (see Additional file 13). For the maintainer line(HZS), the expression levels of these genes were similar between leaves and developing anthers; while for the CMS-C male-sterile line (CHZS), most of them were highly expressed in anthers during meiosis I. Compared with the maintainer line, all of these genes tended to show higher transcription levels at meiosis I in the malesterile line. Three (GRMZM2G120857, GRMZM2G01 8566, GRMZM2G025366) and six (GRMZM2G807639, GRMZM2G151041, GRMZM2G142863, GRMZM2G3 35657, GRMZM2G079538, GRMZM2G151169) genes were found to participate in the IDH and OGDH complexes, respectively, both of which are key enzymes in the TCA cycle. Our additional ELISA experiments showed that the abundance of both IDH and OGDH was significantly higher in NIL_Rf4 than in NIL_rft (Fig. 7). The above results indicated that the genes related to the TCA cycle were associated with CMS-C male fertility.

\section{Discussion}

As a dominant restorer gene for CMS-C, $R f 4$ has great potential value in hybrid maize seed production. Understanding the function approach of $R f 4$ will also benefit for revealing the abortive mechanism of maize CMS-C. Until now, the $R f 4$ candidate gene had not been confirmed, and its functional mechanism was unknown. In this study, lines that were nearly isogenic at the Rft locus were developed for comparative transcriptome analysis to uncover its function. The results of the genetic analysis and genotype characterization proved that the NIL_Rf4 male fertility was restored just by Rf4. Genome-Seq was used to reveal the genomic variation in the NILs, and the results confirmed that most of the SNPs were crowded near the Rf4 location. However, many SNPs were also gathered near the middle of chromosome 2. Various genomic differences clustering in the non-object area of NILs have also been reported in other studies [31]. In fact, NILs always present extensive residual heterozygosity because of the complexity of genomic composition and recombination [32, 33]. Moreover, previous studies in which SNP chips were used have generally reported the 
Table 2 Annotations of energy metabolism-related DEGs

\begin{tabular}{|c|c|c|c|c|}
\hline Gene ID & $\log _{2}$ Fold Change & Direction $^{a}$ & Metabolism Process & Description \\
\hline GRMZM2G345493 & -11.00 & down & Glycolysis/Pentose phosphate pathway & $\begin{array}{l}\text { Fructose-bisphosphate } \\
\text { aldolase } 7 \text { cytosolic }\end{array}$ \\
\hline GRMZM5G836250 & -9.81 & down & Glycolysis/Pentose phosphate pathway & $\begin{array}{l}\text { Fructose-1,6- } \\
\text { bisphosphatase cytosolic }\end{array}$ \\
\hline GRMZM2G134256 & -7.14 & down & Pentose phosphate pathway & Transaldolase 2 \\
\hline GRMZM2G046284 & -6.94 & down & Glycolysis/Pentose phosphate pathway & $\begin{array}{l}\text { Fructose-bisphosphate } \\
\text { aldolase }\end{array}$ \\
\hline GRMZM2G046804 & -6.85 & down & Glycolysis & $\begin{array}{l}\text { Glyceraldehyde-3- } \\
\text { phosphate dehydrogenase, } \\
\text { cytosolic } 1\end{array}$ \\
\hline GRMZM2G001696 & -6.84 & down & Glycolysis/Pyruvate metabolism & $\begin{array}{l}\text { Phosphoenolpyruvate } \\
\text { carboxykinase1 }\end{array}$ \\
\hline GRMZM2G038791 & -6.07 & down & Pentose phosphate pathway & $\begin{array}{l}\text { Ribose-phosphate } \\
\text { pyrophosphokinase }\end{array}$ \\
\hline GRMZM2G047592 & -5.29 & down & Glycolysis & $\begin{array}{l}\text { Galactose mutarotase-like } \\
\text { superfamily protein }\end{array}$ \\
\hline GRMZM2G080375 & -4.97 & down & Glycolysis/Pentose phosphate pathway & $\begin{array}{l}\text { ATP-dependent 6- } \\
\text { phosphofructokinase } 4 \\
\text { chloroplastic }\end{array}$ \\
\hline GRMZM2G442658 & -4.02 & down & Glycolysis & Alcohol dehydrogenase 1 \\
\hline GRMZM2G155253 & -3.39 & down & Glycolysis/Pyruvate metabolism & $\begin{array}{l}\text { Fructose-bisphosphate } \\
\text { aldolase }\end{array}$ \\
\hline GRMZM2G031107 & -3.23 & down & Pentose phosphate pathway & $\begin{array}{l}\text { Glucose-6-phosphate 1- } \\
\text { dehydrogenase }\end{array}$ \\
\hline GRMZM2G083841 & -3.18 & down & Pyruvate metabolism & $\begin{array}{l}\text { Phosphoenolpyruvate } \\
\text { carboxylase } 1\end{array}$ \\
\hline GRMZM5G852968 & -2.91 & down & Glycolysis & Triosephosphate isomerase \\
\hline GRMZM2G306732 & -2.78 & down & Glycolysis/Pentose phosphate pathway & $\begin{array}{l}\text { Fructose-1,6- } \\
\text { bisphosphatase }\end{array}$ \\
\hline GRMZM2G129513 & -2.69 & down & Pyruvate metabolism & Malate dehydrogenase 6 \\
\hline GRMZM2G026807 & -2.39 & down & Pentose phosphate pathway & $\begin{array}{l}\text { Ribulose-phosphate 3- } \\
\text { epimerase }\end{array}$ \\
\hline GRMZM2G144730 & -2.28 & down & Glycolysis/Pyruvate metabolism & Pyruvate kinase \\
\hline GRMZM2G127546 & -2.09 & down & Glycolysis/Pyruvate metabolism & $\begin{array}{l}\text { Pyruvate dehydrogenase E1 } \\
\text { component subunit beta-3 } \\
\text { chloroplastic }\end{array}$ \\
\hline GRMZM5G870932 & -2.01 & down & Glycolysis/Pyruvate metabolism & $\begin{array}{l}\text { Phosphoenolpyruvate } \\
\text { carboxykinase homologue } \\
2\end{array}$ \\
\hline GRMZM2G415359 & -1.96 & down & Pyruvate metabolism & Malate dehydrogenase 5 \\
\hline GRMZM2G179521 & -1.94 & down & Pentose phosphate pathway & $\begin{array}{l}\text { Glucose-6-phosphate 1- } \\
\text { dehydrogenase }\end{array}$ \\
\hline GRMZM5G8798882 & -1.92 & down & Glycolysis/Pentose phosphate pathway & 6-phosphofructokinase \\
\hline GRMZM2G041356 & -1.80 & down & Glycolysis & Aldose 1-epimerase \\
\hline GRMZM2G152975 & -1.75 & down & Glycolysis & $\begin{array}{l}\text { Putative alcohol } \\
\text { dehydrogenase superfamily } \\
\text { protein }\end{array}$ \\
\hline GRMZM2G033208 & -1.55 & down & Pentose phosphate pathway & Transketolase 1 \\
\hline GRMZM5G824600 & No expression in NIL_Rf4 & down & Glycolysis & $\begin{array}{l}\text { Formaldehyde } \\
\text { dehydrogenase homologue } \\
1\end{array}$ \\
\hline GRMZM2G152981 & 0.40 & up & Glycolysis & $\begin{array}{l}\text { Putative alcohol } \\
\text { dehydrogenase superfamily }\end{array}$ \\
\hline
\end{tabular}


Table 2 Annotations of energy metabolism-related DEGs (Continued)

\begin{tabular}{|c|c|c|c|c|}
\hline Gene ID & $\log _{2}$ Fold Change & Direction $^{a}$ & Metabolism Process & Description \\
\hline & & & & protein \\
\hline GRMZM2G104632 & 1.50 & up & Glycolysis & $\begin{array}{l}\text { Glyceraldehyde-3- } \\
\text { phosphate dehydrogenase, } \\
\text { cytosolic }\end{array}$ \\
\hline GRMZM2G057823 & 1.53 & up & Glycolysis/Pentose phosphate pathway & Aldolase 1 \\
\hline GRMZM2G335657 & 1.56 & up & Glycolysis/Pyruvate metabolism & $\begin{array}{l}\text { Dihydrolipoyl } \\
\text { dehydrogenase }\end{array}$ \\
\hline GRMZM2G104081 & 1.64 & up & Glycolysis & Hexokinase 1 \\
\hline GRMZM2G069542 & 1.85 & up & Pyruvate metabolism & $\begin{array}{l}\text { Phosphoenolpyruvate } \\
\text { carboxylase } 7\end{array}$ \\
\hline GRMZM2G466833 & 1.92 & up & Pyruvate metabolism & Malate dehydrogenase3 \\
\hline GRMZM2G180625 & 1.93 & up & Glycolysis & $\begin{array}{l}\text { Cytosolic glyceroldehyde-3- } \\
\text { phosphate dehydrogenase } \\
\text { GAPC2 }\end{array}$ \\
\hline GRMZM2G023289 & 2.02 & up & Glycolysis/Pentose phosphate pathway & Phosphoglucomutase 2 \\
\hline GRMZM2G043198 & 2.07 & up & Glycolysis/Pentose phosphate pathway & Pyruvate dehydrogenase 2 \\
\hline GRMZM2G097226 & 2.15 & up & Glycolysis/Pyruvate metabolism & $\begin{array}{l}\text { Pyruvate dehydrogenase E1 } \\
\text { beta subunit }\end{array}$ \\
\hline GRMZM2G125233 & 2.28 & up & Glycolysis & $\begin{array}{l}\text { Galactose mutarotase-like } \\
\text { superfamily protein }\end{array}$ \\
\hline GRMZM2G440208 & 2.43 & up & Pentose phosphate pathway & $\begin{array}{l}\text { 6-phosphogluconate } \\
\text { dehydrogenase, } \\
\text { decarboxylating }\end{array}$ \\
\hline GRMZM2G098346 & 2.50 & up & Glycolysis & Alcohol dehydrogenase 2 \\
\hline GRMZM2G066024 & 2.52 & up & Glycolysis/Pentose phosphate pathway & $\begin{array}{l}\text { Fructose-bisphosphate } \\
\text { aldolase cytoplasmic } \\
\text { isozyme }\end{array}$ \\
\hline GRMZM2G139360 & 2.54 & up & Glycolysis/Pentose phosphate pathway & $\begin{array}{l}\text { ATP-dependent 6- } \\
\text { phosphofructokinase } 5 \\
\text { chloroplastic }\end{array}$ \\
\hline GRMZM2G136918 & 2.73 & up & Pentose phosphate pathway & $\begin{array}{l}\text { Putative 6- } \\
\text { phosphogluconolactonase } 1\end{array}$ \\
\hline GRMZM2G058702 & 2.74 & up & Glycolysis/Pyruvate metabolism & $\begin{array}{l}\text { Dihydrolipoyllysine-residue } \\
\text { acetyltransferase } \\
\text { component } 4 \text { of pyruvate } \\
\text { dehydrogenase complex } \\
\text { chloroplastic }\end{array}$ \\
\hline GRMZM2G162663 & 2.84 & up & Glycolysis/Pyruvate metabolism & $\begin{array}{l}\text { Acetyl-coenzyme A } \\
\text { synthetase chloroplastic/ } \\
\text { glyoxysomal }\end{array}$ \\
\hline GRMZM2G161245 & 2.96 & up & Pyruvate metabolism & Malate dehydrogenase \\
\hline GRMZM5G860137 & 3.01 & up & Pyruvate metabolism & $\begin{array}{l}\text { Acetyl-CoA } \\
\text { acetyltransferase, cytosolic } 2\end{array}$ \\
\hline GRMZM2G177947 & 3.12 & up & Glycolysis/Pyruvate metabolism & Pyruvate kinase \\
\hline GRMZM2G110714 & 3.18 & up & Pyruvate metabolism & $\begin{array}{l}\text { Phosphoenolpyruvate } \\
\text { carboxylase } 3\end{array}$ \\
\hline GRMZM2G074122 & 3.25 & up & Pyruvate metabolism & $\begin{array}{l}\text { Phosphoenolpyruvate } \\
\text { carboxylase isoform } 1\end{array}$ \\
\hline GRMZM2G322953 & 3.42 & up & Glycolysis & $\begin{array}{l}\text { Fructose-1,6- } \\
\text { bisphosphatase, cytosolic }\end{array}$ \\
\hline GRMZM2G003385 & 3.53 & up & Glycolysis/Pentose phosphate pathway & $\begin{array}{l}\text { 2,3-bisphosphoglycerate- } \\
\text { independent } \\
\text { phosphoglycerate mutase } 1\end{array}$ \\
\hline GRMZM5G886257 & 4.17 & up & Pyruvate metabolism & NADP-dependent malic \\
\hline
\end{tabular}


Table 2 Annotations of energy metabolism-related DEGs (Continued)

\begin{tabular}{lllll}
\hline Gene ID & $\log _{2}$ Fold Change & Direction $^{a}$ & Metabolism Process & Description \\
\hline GRMZM2G146206 & 4.19 & up & Glycolysis & enzyme \\
GRMZM2G003354 & 4.62 & up & Glycolysis & $\begin{array}{l}\text { Triosephosphate isomerase, } \\
\text { cytosolic }\end{array}$ \\
GRMZM2G154007 & 12.00 & up & Glycolysis & $\begin{array}{l}\text { Apospory-associated } \\
\text { protein C }\end{array}$ \\
GRMZM2G071630 & No expression in NIL_rf4 & up & Glycolysis & Alcohol dehydrogenase-like \\
& & & & 2
\end{tabular}

Direction means relative to the expression level in NIL_Rf4

presence of SNPs between NILs [34-36]. Compared to SNP chips, next-generation sequencing has a broader and more sensitive detection ability, which might also explain why we detected more SNPs than did previous researchers.

Insufficient energy supplies can impair male gamete development but not vegetative organs, ultimately causing male sterility [2]. Previous studies have also shown that a close relationship exists between pollen dysfunction and energy metabolism in CMS-C. Three ATP-synthesizing chimeric ORFs, i.e., atp9-c, cox2-c, and atp6-c, were first identified in CMS-C plants [37].
Nevertheless, Meyer did not observe any chimeric proteins but did report that the expression of several ATP synthase complex proteins decreased within CMS-C tassels [38]. It can be inferred that pollen abortion in CMS-C plants is caused by inadequate ATP production because of the low atp9-c translation efficiency. Moreover, our group analysed the differences between the male-sterile line (C48-2) and its maintainer line $\mathrm{N} 48-2$, and we found that some DEGs and differentially expressed proteins were related to energy metabolism $[39,40]$. At the metabolic level, compared to the anthers of the

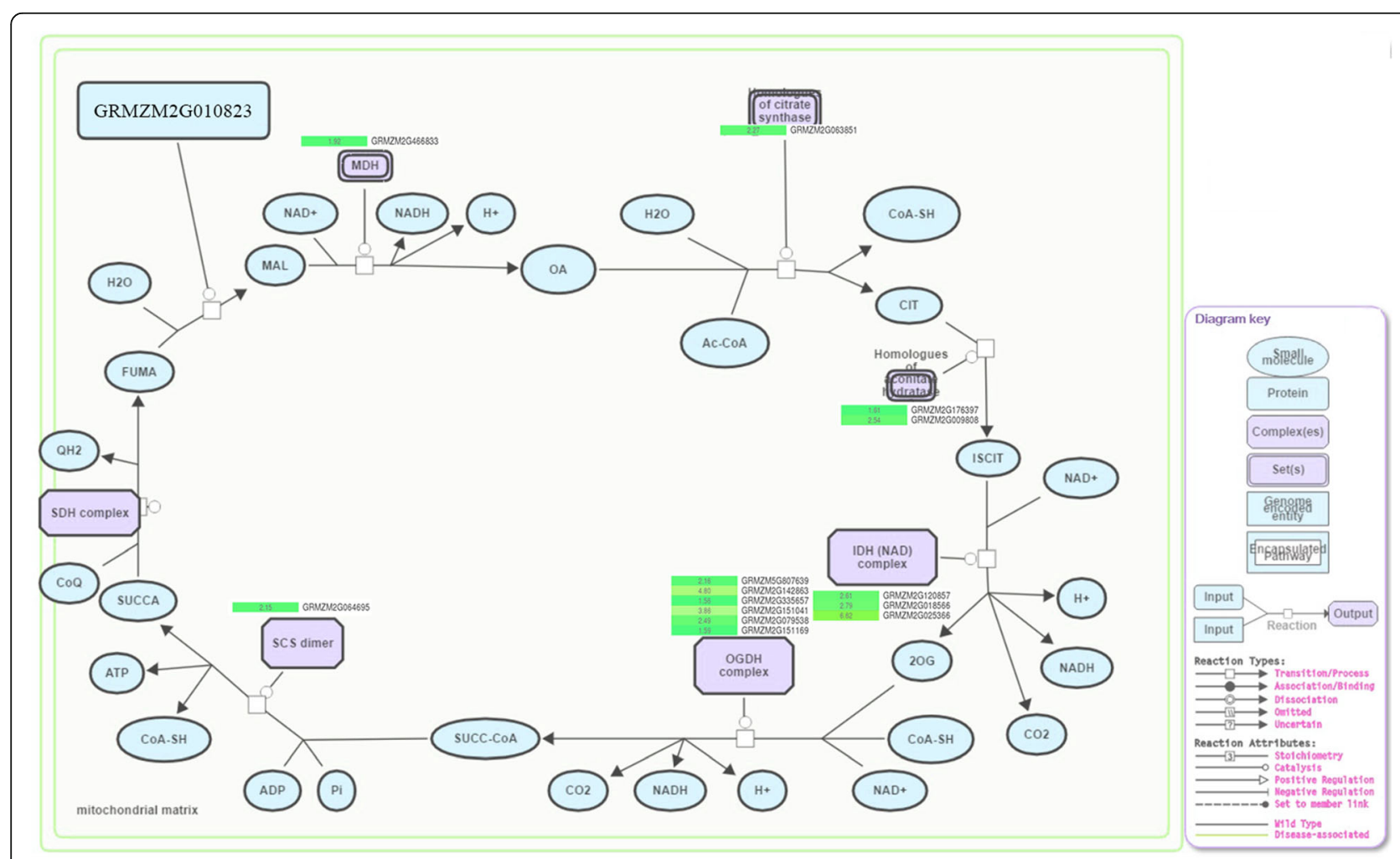

Fig. 5 Identification of DEGs involved in the mitochondrial TCA cycle. The number indicates the gene expression fold changes that were log 2 transformed in NIL_Rf4 compared with NIL_rf4 

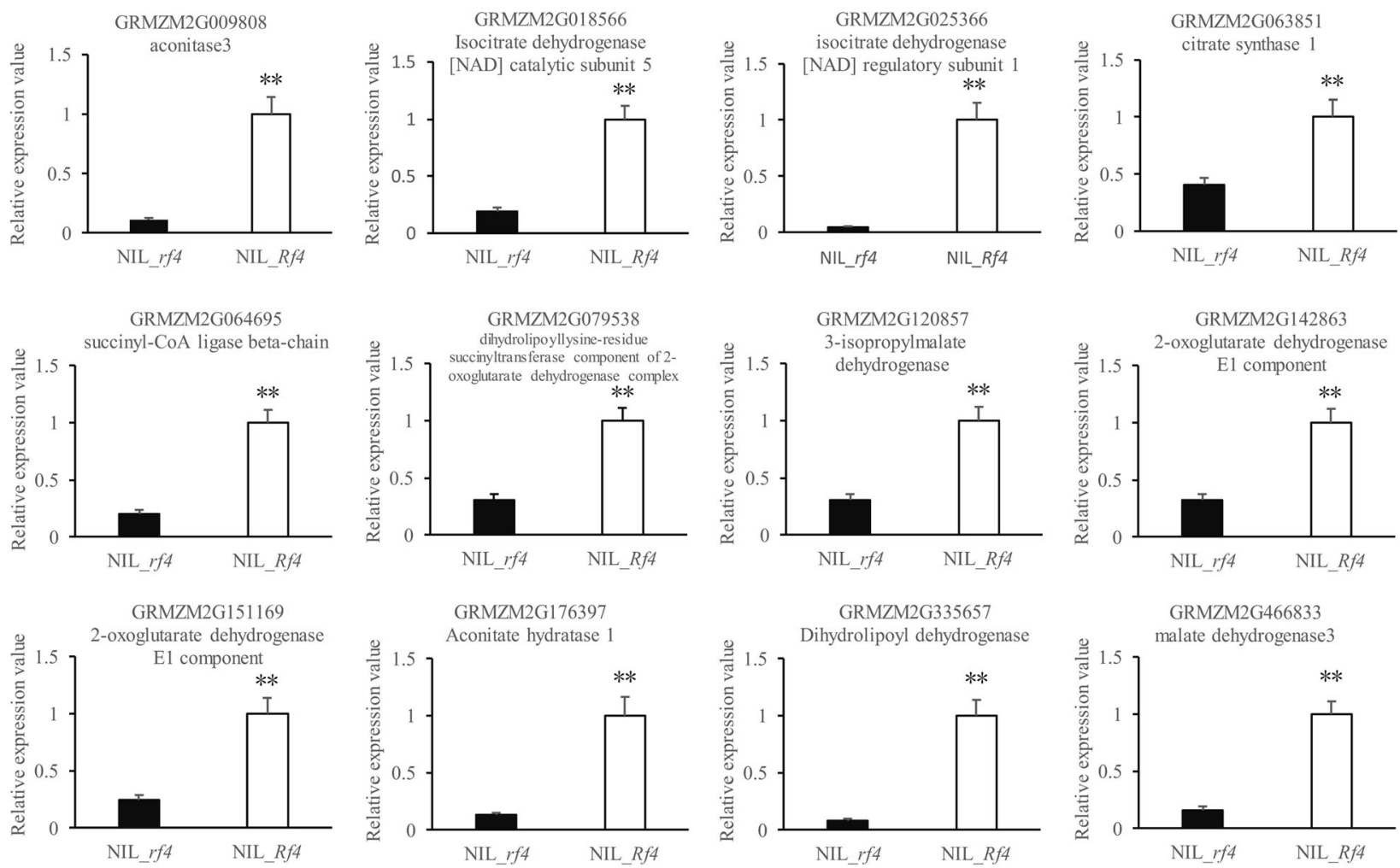

Fig. 6 qPCR confirmation of genes associated with the mitochondrial TCA cycle. The data are given as means \pm SEMs of three biological replicates. Independent Student's $t$-tests were used to calculate the $P$ values. ${ }^{*} P<0.01$

maintainer line, the anthers of the CMS-C line always present lower levels of respiratory intensity, cyanide-resistant respiration, cytochrome oxidase activity and ATP content during microspore development $[41,42]$. In the present study, elevated IDH and OGDH enzyme levels were detected in the male fertility-restored line. Both IDH and OGDH are $\mathrm{NADH}$-synthesizing enzymes and play a key role in the mitochondrial TCA cycle, which determines the

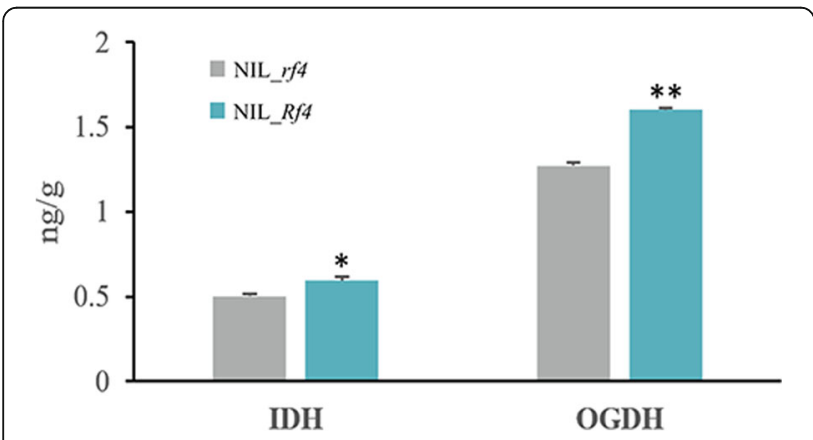

Fig. 7 Comparison of IDH and OGDH enzyme levels between NIL_Rf4 and NIL_rf4. The data are presented as the means \pm SEMs of three biological replicates. Each replicate consisted of three technical replicates. The asterisks represent statistically significant differences between NIL_Rf4 and NIL_rf4 at $P<0.05\left(^{*}\right)$ or $P<0.01 \quad(* *)$ (Independent Student's t-test) energy supply in cells $[29,30]$. Down-regulation of the mitochondrial citrate synthase enzyme ultimately causes male sterility [43]. Our results provided new evidence for the association between the mitochondrial TCA cycle and plant male fertility. Interestingly, when compared with the CMS-C male-sterile line, these TCA cycle-related genes were up-regulated in anthers of NIL_Rf4 while down-regulated in maintainer line anthers. These results revealed the probable existence of different energy metabolism-related genes expression levels between the maintainer line and NIL_Rf4 although they both were male fertile. This hypothesis needs to be further verified because the difference might also be caused by different pollen developmental stages in comparison.

With the exception of those in maize, many studies about CMS in other species show that, compared with normal lines, CMS lines always appear to have lower energy metabolism levels [44-46]. Mitochondria play an essential role in supplying cellular energy. Most mitochondrial proteins are encoded by nuclear genes; these proteins are synthesized in the cytoplasm and then imported into the mitochondria [47]. Recently, increasing amounts of attention have been paid to the connection between these nuclear- 
encoded mitochondrial proteins and CMS fertility restoration. $R f 2$ encodes a mitochondrial aldehyde dehydrogenase (ALDH) enzyme, and its expression can rescue maize T-type cytoplasmic male sterility (CMS-T) [48, 49]. Both GRP162 and RFC3 proteins accumulate within mitochondria and can directly interact with $R f 5$ to rescue HongLian cytoplasmic male sterility (HL-CMS) in rice $[50,51]$. Hexokinase 6 is a mitochondrial-localized protein whose interaction with $R f 6$ is necessary for HL-CMS fertility restoration [52]. This report provided direct evidence that energy metabolism-related genes directly contribute to plant CMS fertility restoration. In our experiments, 14 up-regulated genes involved in the TCA cycle were identified; however, their detailed function in restoring the fertility of maize CMS-C requires further study.

\section{Conclusions}

Lines that were nearly isogenic at the Rf4 locus were developed and characterized via genetic analysis, molecular marker detection and whole-genome sequencing. Comparative transcriptome analysis between male-fertile NIL_Rf4 plants and male-sterile NIL_rf4 plants revealed several crucial genes and metabolic pathways during CMS-C male fertility restoration. Interestingly, all of the DEGs involved in the mitochondrial TCA cycle were up-regulated in the male-fertile NIL_Rf4 plants, and most of those DEGs tended to be involved in the IDH and OGDH complexes. Our ELISA results demonstrated that the abundance of both the IDH and OGDH enzymes was higher in NIL_Rf4 than in NIL_rf4, indicating that the IDH and OGDH enzymes might be related to maize CMS-C fertility restoration. These results expand the current understanding of maize CMS-C male fertility restoration.

\section{Additional files}

Additional file 1: List of primers used for GPCR in this study. 18S RNA was used as an internal control. (XLSX $12 \mathrm{~kb}$ )

Additional file 2: Comparisons of male-fertile tassels (a), anthers (b), and pollen (c) between NIL_Rf4 and NIL_rf4. In Fig. (c), the pollen grains were stained with $1 \%(\mathrm{~W} / \mathrm{V}) \mathrm{KI}-\mathrm{I}_{2}$. (TIF $787 \mathrm{~kb}$ )

Additional file 3: Fertility segregations of the $\mathrm{BC}_{4}$ and $\mathrm{BC}_{5}$ populations. $A$ chi-squared test was used to evaluate the fertility segregation ratios. (XLSX $11 \mathrm{~kb})$

Additional file 4: Genotype analysis of the $\mathrm{BC}_{5}$ population via the dominant Rf4 tightly linked marker (5'-CGCACCTAACCGTCTCC-3', 5'-GCGC AAGTACGCCGTAC-3'). F, fertile individuals; S, sterile individuals. (TIF 129 $\mathrm{kb})$

Additional file 5: Validation of SNPs within the coding sequence of GRMZM2G122850. (TIF $191 \mathrm{~kb}$ )

Additional file 6: Coding sequences of novel genes. (TXT $1323 \mathrm{~kb}$ )

Additional file 7: Function annotations of novel genes. (XLSX $315 \mathrm{~kb}$ )

Additional file 8: All DEGs with exonic SNPs. (XLSX $504 \mathrm{~kb}$ )
Additional file 9: Two hundred forty-two significantly enriched $\mathrm{GO}$ terms obtained by Fisher's test $(Q \leq 0.05)$. (XLSX $20 \mathrm{~kb})$

Additional file 10: DEGs homologous to Arabidopsis male sterility (MS)/ reproduction (MR) genes. (XLSX $35 \mathrm{~kb}$ )

Additional file 11: Expression patterns of male reproduction-related DEGs. Their expression values (FPKM) were retrieved from the qTeller website (www.qteller.com), and the FPKM values were $\log _{2}$ transformed by (FPKM + 1); a Z-score was then calculated for each gene. (TIF $298 \mathrm{~kb}$ )

Additional file 12: Identification of PPR genes among DEGs. "Direction" means relative to the expression level in NIL_Rf4. (XLSX $13 \mathrm{~kb}$ )

Additional file 13: (a)Tissue expression profile of 14 TCA cycle-related DEGs. The expression data (FPKM values) were obtained from qTeller (www.qteller.com). The FPKM values were $\log _{2}$ transformed (FPKM + 1), and a Z-score was calculated for each gene. (b) Comparison of TCArelated DEGs expression levels between the male-sterile line $\mathrm{CHZS}$ and its maintainer line $\mathrm{HZS} . \mathrm{A} 1, \mathrm{~A} 2$, and $\mathrm{A} 3$ denote developing anthers with the length of $1.5 \sim 2.0 \mathrm{~mm}$ (meiosis I), 2.0 $2.5 \mathrm{~mm}$ (meiosis II) and 2.5 $3.0 \mathrm{~mm}$ (uninucleate microspore) respectively. The data are given as means \pm SEMs of at least three biological replicates. The relationship between maize pollen development stage and anther lenght can be found in another report [53]. (TIF $466 \mathrm{~kb}$ )

\section{Abbreviations}

ALDH: aldehyde dehydrogenase; CMS: cytoplasmic male sterility; CMS-C: C-type cytoplasmic male sterility; CMS-T: T-type cytoplasmic male sterility; DEGs: differentially expressed genes; ELISA: enzyme-linked immunosorbent assay; FPKM: fragments per kilobase of exon per million fragments mapped; GO: Gene Ontology; HL-CMS: HongLian cytoplasmic male sterility; HMM: Hidden Markov Motif; IDH: isocitrate dehydrogenase; KEGG: Kyoto Encyclopedia of Genes and Genomes; NIL: near-isogenic line;

OGDH: oxoglutarate dehydrogenase; ORF: opening reading frame; PMRD: Plant Male Reproduction Database; PPR: pentatricopeptide repeat; qPCR: real-time quantitative PCR; QTL: quantitative trait locus; Rf: restorer of fertility; SNP: Single nucleotide polymorphism; TCA: tricarboxylic acid; TPM: transcripts per million; UTR: untranslated region

\section{Acknowledgements}

We thank colleagues at Novogene (Beijing, China) and Basebio (Chengdu, China) for their help in interpreting the genomic and transcriptomic data.

\section{Funding}

The present work was supported by the National Key Research and Development Program of China (2016YFD0101206) and the Science and Technology Department of Sichuan Province (2016NZ0106).

\section{Availability of data and materials}

The Genome-Seq and transcriptome sequencing raw data generated and analysed during the current study are available in the Fig SHARE repository (https://doi.org/10.6084/m9.figshare.5709637.v1, https://doi.org/10.6084/ m9.figshare.5709646.v1, https://doi.org/10.6084/m9.figshare.5709658.v1).

\section{Authors' contributions}

YML designed the research, performed most of the experiments, and wrote the paper. GW performed most of the experiments and analysed the results. YYX, XWL, and JT performed part of the experiments. YLL, HL, SZZ, and CL provided advice for the experiment. MJC designed the research and revised the paper. All authors reviewed and approved the final manuscript.

Ethics approval and consent to participate

Not applicable.

Consent for publication

Not applicable.

\section{Competing interests}

The authors declare that they have no competing interests. 


\section{Publisher's Note}

Springer Nature remains neutral with regard to jurisdictional claims in published maps and institutional affiliations.

Received: 2 January 2018 Accepted: 31 August 2018

Published online: 12 September 2018

\section{References}

1. Chen Z, Zhao N, Li S, Grover CE, Nie H, Wendel JF, Hua J. Plant mitochondrial genome evolution and cytoplasmic male sterility. Crit Rev Plant Sci. 2017:36(1):55-69.

2. Chen L, Liu Y. Male sterility and fertility restoration in crops. Annu Rev Plant Biol. 2014;65:579-606.

3. Hu J, Huang W, Huang Q, Qin X, Yu C, Wang L, Li S, Zhu R, Zhu Y. Mitochondria and cytoplasmic male sterility in plants. Mitochondrion. 2014; $19 \cdot 282-8$

4. Touzet P, Meyer EH. Cytoplasmic male sterility and mitochondrial metabolism in plants. Mitochondrion. 2014;19:166-71.

5. Kim Y, Zhang D. Molecular control of male fertility for crop hybrid breeding. Trends Plant Sci. 2017:23(1):53-65.

6. Bohra A, Jha UC, Adhimoolam P, Bisht D, Singh NP. Cytoplasmic male sterility (CMS) in hybrid breeding in field crops. Plant Cell Rep. 2016;35(5): 967-93.

7. Beckett JB. Classification of male-sterile cytoplasms in maize (Zea mays L.) Crop Sci. 1971;11(5):724-7.

8. Weider C, Stamp P, Christov N, Husken A, Foueillassar X, Camp K, Munsch M. Stability of cytoplasmic male sterility in maize under different environmental conditions. Crop Sci. 2009;49(1):77-84

9. Stevanovic M, Camdzija Z, Pavlov J, Markovic K, Vancetovic J, Drinic SM, Filipovic M. The application of protein markers in conversion of maize inbred lines to the cytoplasmic male sterility basis. Genetika. 2016;48:691-8.

10. Qin TC, Xu ML, Dun DX. Cytoplasmic male-sterility: identification of the number of the restorer genes. Maize Genetics Coop News Lett. 1990;64:124.

11. Chen $\mathrm{S}, \mathrm{Chen} \mathrm{W}$. The chromosomal location of restoring genes of $\mathrm{C}$ cytoplasmic male-sterile in maize. Acta Agric Univ Henanensis. 1992;26(2): 125-30.

12. Kohls S, Stamp P, Knaak C, Messmer R. QTL involved in the partial restoration of male fertility of C-type cytoplasmic male sterility in maize. Theor Appl Genet. 2011;123(2):327-38

13. Hu YM, Tang JH, Yang H, Xie HL, Lu XM, Niu JH, Chen WC. Identification and mapping of $R f-I$ an inhibitor of the Rf5 restorer gene for $\mathrm{cms}-\mathrm{C}$ in maize (Zea mays L.). Theor Appl Genet. 2006;113(2):357-60.

14. Liu Y, Zhao Z, Lu Y, Li C, Wang J, Dong B, Liang B, Qiu T, Zeng W, Cao M. A preliminary identification of $\mathrm{Rf}^{*}$-A619, a novel restorer gene for CMS-C in maize (Zea mays L.). PEERJ. 2016:4:e2719.

15. Sisco PH. Duplications complicate genetic mapping of $R f 4$, a restorer gene for cms-C cytoplasmic male sterility in corn. Crop Sci. 1991;31(5):1263-6.

16. Tang J, Ji H, Huang Z, Ji L, Wang C. Mapping of the main restoring gene (Rf4) of C-cytoplasmic male sterility in maize with RFLP. Acta Agriculturae Univ Henanensis. 2000;35(2):99-102.

17. Tang J, Hu Y, Ji H, Chen W, Ji L, Zhen Y. The SSR marker of the restoring gene Rf4 for CMS-C cytoplasmic male sterility in maize. J Henan Agric Univ. 2001;35(1):1-03.

18. Kohls S. Unraveling genetic factors controlling the restoration of fertility of C-type cytoplasmic male sterility in maize. 2010. https://doi.org/10.3929/ ethz-a-006391548. Accessed 13 Jun 2017.

19. Ren R, Nagel BA, Kumpatla SP, Zheng P, Cutter G, Greene TW, Thompson SA. Maize cytoplasmic male sterility (cms) c-type restorer rf4 gene, molecular markers and their use. 2011. https:// www.google.com/ patents/ US20120090047. Accessed 12 Dec 2012

20. Dahan J, Mireau H. The Rf and Rf-like PPR in higher plants, a fast-evolving subclass of PPR genes. RNA Biol. 2013;10(9):1469-76.

21. Gaborieau L, Brown GG, Mireau H. The propensity of Pentatricopeptide repeat genes to evolve into restorers of cytoplasmic male sterility. FRONT. Plant Sci. 2016:7:e1002910.

22. Porebski S, Bailey LG, Baum BR. Modification of a CTAB DNA extraction protocol for plants containing high polysaccharide and polyphenol components. Plant Mol Biol Rep. 1997;15(1):8-15.

23. Li H, Durbin R. Fast and accurate short read alignment with burrowswheeler transform. Bioinformatics. 2010;25(5):1754-60.
24. Abe A, Kosugi S, Yoshida K, Natsume S, Takagi H, Kanzaki H, Matsumura H, Yoshida K, Mitsuoka C, Tamiru M. Genome sequencing reveals agronomically important loci in rice using MutMap. Nat Biotechnol. 2012;30(2):174-8.

25. Takagi H, Abe A, Yoshida K, Kosugi S, Natsume S, Mitsuoka C, Uemura A, Utsushi H, Tamiru M, Takuno S. QTL-seq: rapid mapping of quantitative trait loci in rice by whole genome resequencing of DNA from two bulked populations. Plant J. 2013;74(1):174-83.

26. Wagner GP, Kin K, Lynch VJ. Measurement of mRNA abundance using RNAseq data: RPKM measure is inconsistent among samples. Theor Biosci. 2012; 131(4):281-5.

27. Wei K, Han P. Pentatricopeptide repeat proteins in maize. Mol Breeding. 2016;36:170

28. Livak KJ, Schmittgen TD. Analysis of relative gene expression data using real-time quantitative PCR and the 2(-Delta Delta C(T)) method. Methods. 2001:25(4):402-8.

29. Zhang Y, Fernie AR. On the role of the tricarboxylic acid cycle in plant productivity. 2018; https://doi.org/10.1111/jipb.12690.

30. Nunes-Nesi A, Araújo WL, Obata T, Fernie AR. Regulation of the mitochondrial tricarboxylic acid cycle. Curr Opin Plant Biol. 2013;16(3):335-43.

31. Liang J, Ma Y, Wu J, Cheng F, Liu B, Wang X. Map-based cloning of the dominant genic male sterile Ms-cd1 gene in cabbage (Brassica oleracea). Theor Appl Genet. 2017;130(1):71-9.

32. Gaut BS, Wright SI, Rizzon C, Dvorak J, Anderson LK. Recombination: an underappreciated factor in the evolution of plant genomes. Nat Rev Genet. 2007:8(1):77-84

33. Eichten SR, Foerster JM, de Leon N, Kai Y, Yeh C, Liu S, Jeddeloh JA, Schnable PS, Kaeppler SM, Springer NM. B73-Mo17 near-isogenic lines demonstrate dispersed structural variation in maize. Plant Physiol. 2011; 156(4):1679-90

34. Pea G, Aung HH, Frascaroli E, Landi P, Pè ME. Extensive genomic characterization of a set of near-isogenic lines for heterotic QTL in maize (Zea mays L.). BMC Genomics. 2013;14(1):61.

35. Brinton J, Simmonds J, Minter F, Leverington Waite M, Snape J, Uauy C. Increased pericarp cell length underlies a major quantitative trait locus for grain weight in hexaploid wheat. New Phytol. 2017;215(3):1026-38.

36. Jena KK, Hechanova SL, Verdeprado H, Prahalada GD, Kim S. Development of 25 near-isogenic lines (NILs) with ten BPH resistance genes in rice (Oryza sativa L.): production, resistance spectrum, and molecular analysis. Theor Appl Genet. 2017;130(11):2345-60.

37. Dewey RE, Timothy DH, Levings CS III. Chimeric mitochondrial genes expressed in the C male-sterile cytoplasm of maize. Curr Genet. 1991;20(6):475-82.

38. Meyer $L$. Investigations into the cause of pollen abortion in maize CMS-C. 2009. http://hdl.handle.net/10355/9563. Accessed May 2009.

39. Huang L, Xiang J, Liu J, Rong T, Wang J, Lu Y, Tang Q, Wen W, Cao M. Expression characterization of genes for CMS-C in maize. Protoplasma. 2012; 249(4):1119-27

40. Li C, Zhao Z, Liu Y, Liang B, Guan S, Lan H, Wang J, Lu Y, Cao M. Comparative transcriptome analysis of isonuclear-alloplasmic lines unmask key transcription factor genes and metabolic pathways involved in sterility of maize CMS-C. PeerJ. 2017;5:e3408.

41. Xia T, Liu J. Study on the relation between cytoplasmic male sterility in maize and CN-resistant respiration in tissues. Sci Agric Sin. 1988;21(5):39-43.

42. Xia T, Liu J. Cytochrome oxidase Acitivity and ATP content of male-sterile cytoplasm in maize (Zea mays L.). Acta Agriculturae Boreali-Sinica. 1994;9(4): 33-7.

43. Landschutze V, Willmitzer L, Muller Rober B. Inhibition of flower formation by antisense repression of mitochondrial citrate synthase in transgenic potato plants leads to a specific disintegration of the ovary tissues of flowers. Embo J. 1995;14(4):660-6.

44. Bergman P, Edqvist J, Farbos I, Glimelius K. Male-sterile tobacco displays abnormal mitochondrial atp1 transcript accumulation and reduced flora ATP/ADP ratio. Plant Mol Biol. 2000:42(3):531-44.

45. Teixeira RT, Knorpp C, Glimelius K. Modified sucrose, starch, and ATP levels in two alloplasmic male-sterile lines of B. napus. J Exp Bot. 2005;56(414):1245-53.

46. Li J, Han S, Ding X, He T, Dai J, Yang S, Gai J. Comparative transcriptome analysis between the cytoplasmic male sterile line NJCMS1A and its maintainer NJCMS1B in soybean (Glycine max (L.) Merr). PLoS One. 2015; 10(5):e126771.

47. Taanman J. The mitochondrial genome: structure, transcription, translation and replication. Biochimica et Biophysica Acta (BBA)-Bioenergetics. 1999; 1410(2):103-23. 
48. Cui X, Wise RP, Schnable PS. The rf2 nuclear restorer gene of male-sterile T-cytoplasm maize. Science. 1996;272(5266):1334-6.

49. Liu F, Cui X, Horner HT, Weiner H, Schnable PS. Mitochondrial aldehyde dehydrogenase activity is required for male fertility in maize. Plant Cell. 2001;13(5):1063-78.

50. Hu J, Wang K, Huang W, Liu G, Gao Y, Wang J, Huang Q, Ji Y, Qin X, Wan L, et al. The rice pentatricopeptide repeat protein RF5 restores fertility in Hong-Lian cytoplasmic male-sterile lines via a complex with the glycine-rich protein GRP162. Plant Cell. 2012;24(1):109-22.

51. Qin X, Huang Q, Xiao H, Zhang Q, Ni C, Xu Y, Liu G, Yang D, Zhu Y, Hu J. The rice DUF1620-containing and WD40-like repeat protein is required for the assembly of the restoration of fertility complex. New Phytol. 2016;210(3): 934-45.

52. Huang W, Yu C, Hu J, Wang L, Dan Z, Zhou W, He C, Zeng Y, Yao G, Qi J. Pentatricopeptide-repeat family protein RF 6 functions with hexokinase 6 to rescue rice cytoplasmic male sterility. Proc Natl Acad Sci. 2015;112(48): 14984-9.

53. Zhai J, Zhang H, Arikit S, Huang K, Nan G, Walbot V, Meyers BC. Spatiotemporally dynamic, cell-type-dependent premeiotic and meiotic phasiRNAs in maize anthers. Proc Natl Acad Sci. 2015;112(10):3146-51.

Ready to submit your research? Choose BMC and benefit from:

- fast, convenient online submission

- thorough peer review by experienced researchers in your field

- rapid publication on acceptance

- support for research data, including large and complex data types

- gold Open Access which fosters wider collaboration and increased citations

- maximum visibility for your research: over $100 \mathrm{M}$ website views per year

At $\mathrm{BMC}$, research is always in progress.

Learn more biomedcentral.com/submissions 